\title{
Simple Current-Mode Squaring and Square-Rooting Circuits: Applications of MO-CCCCTA
}

\author{
Suvajit Roy, Tapas Kumar Paul and Radha Raman Pal* \\ Department of Physics, Vidyasagar University, Midnapore, West Bengal 721102, India
}

('Corresponding author's e-mail: rrpal@mail.vidyasagar.ac.in)

Received: 12 December 2020, Revised: 2 June 2021, Accepted: 12 June 2021

\begin{abstract}
This work provides new designs of simple current-mode squaring and square-rooting circuits using multiple-output current controlled current conveyor transconductance amplifier (MO-CCCCTA) as an active building block. Since the proposed circuits need no other external components, they are capable of high-frequency operation and well fitted for IC fabrication. Furthermore, they are insensitive to ambient temperature and their gains can be controlled easily by adjusting the bias currents of MO-CCCCTA. Additionally, the effects of MO-CCCCTA non-idealities on the designed circuits have also been investigated and discussed. Simulation results generated through PSPICE software using TSMC $0.18 \mu \mathrm{m}$ CMOS process parameters have been presented to justify the theoretical analysis. The static power consumption, bandwidth, and maximum linearity error in dc transfer characteristic measurement for the square-rooting circuit are found to be $0.17 \mathrm{~mW}, 445.63 \mathrm{MHz}$ and $1.12 \%$, while for the squaring circuit they are $0.326 \mathrm{~mW}, 61.15 \mathrm{MHz}$ and $2.38 \%$, respectively. The application of the reported circuits as a 2input vector summation circuit has also been included to strengthen the design ideas.
\end{abstract}

Keywords: MO-CCCCTA, Squarer, Square-rooter, Vector summation circuit

\section{Introduction}

Current-mode circuit designing is an appealing research field for decades due to many potential advantages over their voltage-mode counterpart like-wider dynamic range, simpler circuitry, extended signal bandwidth, improved linearity and lower power consumption $[1,2]$. Squaring and square-rooting circuits are very important building blocks extensively used for continuous-time signal processing in analog instrumentation, measurement and communication systems [3]. The root-mean-square value of an arbitrary waveform can also be found employing these circuits [4]. Recently, analog circuit designing using different active building blocks has received a lot of attention. Though several squaring and squarerooting circuits using various active building blocks have been reported earlier, they are not free from limitations. Specifically, in [3], 1 squarer and 2 square-rooters using a single current differencing buffer amplifier (CDBA) were introduced, but all of them work in voltage-mode. Moreover, 2 MOSFETs and 1 resistor are needed additionally for the squarer, and 2/4 external MOSFETs are needed for the first/second square-rooter, respectively. The single second-generation current conveyor (CCII) based squaring and square-rooting circuits reported in [5] employing 2 MOSFETs and 1 resistor, also work in voltage-mode. Despite that, an extra buffer circuit is used in the square-rooting circuit. Two square-rooters (one in voltage-mode and another in current-mode) were presented in [4]. The voltage-mode configuration employed 2 second-generation current-controlled current conveyors (CCCIIs), 1 current-controlled resistor and 2 grounded resistors, while the current-mode circuit required 2 CCCIIs and 1 currentcontrolled resistor. Using only CCCIIs, another current-mode squarer and square-rooter were proposed in [6], but 2 and 3 CCCIIs were needed for the square-rooter and the squarer circuit, respectively. The OPAMP based square-rooting circuits informed in [7-10] have the disadvantages that they use excessive passive components and operate in voltage-mode. Also, the circuits of [7-9] employ multiple OP-AMPs. Again, the squaring and square-rooting circuits introduced in [11] employing an OP-AMP and 2/4 MOSFETs are of voltage-modes. Employing a single operational transresistance amplifier (OTRA) and 3 MOSFETs another squaring [12] and square-rooting [13] circuit was proposed, but they are also of voltage-modes. The squaring and square-rooting circuits reported in [14] using 1 differential difference current conveyor (DDCC) and 2 MOSFETs needed a relatively large power supply. Besides, the square- 
rooter also required 1 voltage follower and a voltage-to-current converter. A square-rooter circuit employing 1 operation transconductance amplifier (OTA), 1 buffer and 1 MOSFET was presented in [15], but the circuit works in voltage-mode. The squaring and/or square-rooting circuits reported in [1620] use 3 or more OTAs. Using 2 current differencing transconductance amplifiers (CDTAs) squaring and square-rooting circuits were presented in [21], but the circuits cannot provide current outputs. The single multiple-output current through transconductance amplifier (MO-CTTA) based square-rooter and squarer circuit introduced in [22] required a large power supply. The current mode square-rooting circuits proposed in $[23,24]$ needed 2 active building blocks - namely MO-CFTA and CCCDTA, respectively. The squarer proposed in [25] required 4 current-controlled current differencing buffer amplifiers (CCCDBAs).

In 2008, a new current-mode active device namely the current-controlled current conveyor transconductance amplifier (CCCCTA) was introduced, which is basically a modified version of the current conveyor transconductance amplifier (CCTA) [26]. It resembles the CCTA in all perspectives with an additional feature that its parasitic resistance, $R_{x}$, at the $\mathrm{X}$ terminal can be adjusted through an input bias current. Intuitively, the CCCCTA is a multifunction active device, which provides the chance to exploit its transconductance gain $\left(g_{m}\right)$ and its parasitic resistance $\left(R_{x}\right)$ to make a resistorless design. The multiple current output ports of the CCCCTA can be achieved easily by attaching additional current mirrors at the requisite output ports. In earlier literature, the MO-CCCCTA is shown to give a lot of flexibility in designing various analog signal processing circuits, such as oscillator [26-28], capacitance multiplier [29], inductance simulator [26,30], universal biquad filter [26,31], etc. However, to the best knowledge of the authors, no squaring or square-rooting circuit employing MO-CCCCTA has been reported so far in any open literature. This motivates the authors highly to design new current-mode squaring and square-rooting structures based on MO-CCCCTA.

The major goal of this paper is to propose simple current-mode squaring and square-rooting circuits using MO-CCCCTA as an active device. Usually, a squarer is realized by simply feeding identical inputs in a multiplier. However, the scheme struggles with distortions arising mainly from nonlinearity of the multiplier [6]. A different aspect of this paper is to employ simple architectures comprising only MOCCCCTA active block. Since no other external component has been used here, they are capable of high frequency operation and well suited for IC implementation. Moreover, they have immunity to temperature drift and their transfer gains can be controlled easily by adjusting the bias currents of MO-CCCCTA. The performances of the designed circuits are examined through PSPICE simulations which demonstrate close agreement with theoretical anticipations. Additionally, the application of the reported structures as a 2input vector summation circuit is also included to demonstrate their efficiency.

\section{Circuit description and methodology}

\section{Basic concept of MO-CCCCTA}

Since the designed circuits are based on MO-CCCCTA, a concise description of MO-CCCCTA has been given in this section. Actually, MO-CCCCTA is a combined form of CCCII and OTA [27]. The schematic symbol and the equivalent circuit of the MO-CCCCTA have been displayed in Figures 1a and $\mathbf{1 b}$, respectively. A possible CMOS structure of MO-CCCCTA is given in Figure $\mathbf{2}$ which is a marginally modified version of the structure suggested in [27,31].

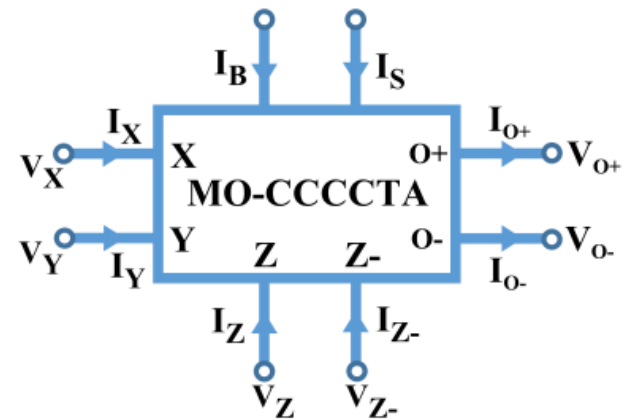

(a)

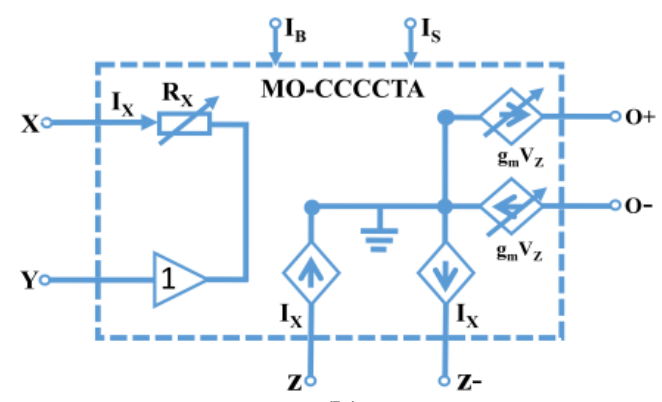

(b)

Figure 1 The MO-CCCCTA (a) schematic symbol and (b) equivalent circuit [28]. 
The ideal terminal characteristics of the MO-CCCCTA utilized in this article can be summarized by the following equation;

$I_{y}=0, V_{x}=V_{y}+I_{x} R_{x}, I_{z}=I_{z c}=-I_{z-}=I_{x}$ and $I_{O+}=-I_{O-}=g_{m} V_{z}$

For a CMOS structure of MO-CCCCTA, the transconductance gain $\left(g_{m}\right)$ and parasitic resistance $\left(R_{x}\right)$ can be written as;

$$
g_{m}=\sqrt{\mu_{n} C_{o x}(W / L)_{22,23} I_{B}} \text { and } R_{x}=\frac{1}{\sqrt{8 \mu_{n} C_{o x}(W / L)_{1,2} I_{S}}}
$$

where $\mu_{n}$ and $C_{o x}$ represent the mobility of electron and gate-oxide capacitance per unit area, respectively. $(\mathrm{W} / \mathrm{L})_{1,2}$ represent the aspect ratio of $\mathrm{M}_{1}$ or $\mathrm{M}_{2}$ and $(\mathrm{W} / \mathrm{L})_{22,23}$ represent the same for $\mathrm{M}_{22}$ or $\mathrm{M}_{23}$. The bias currents $I_{B}$ and $I_{S}$ are used to control the transconductance gain and parasitic resistance, respectively.

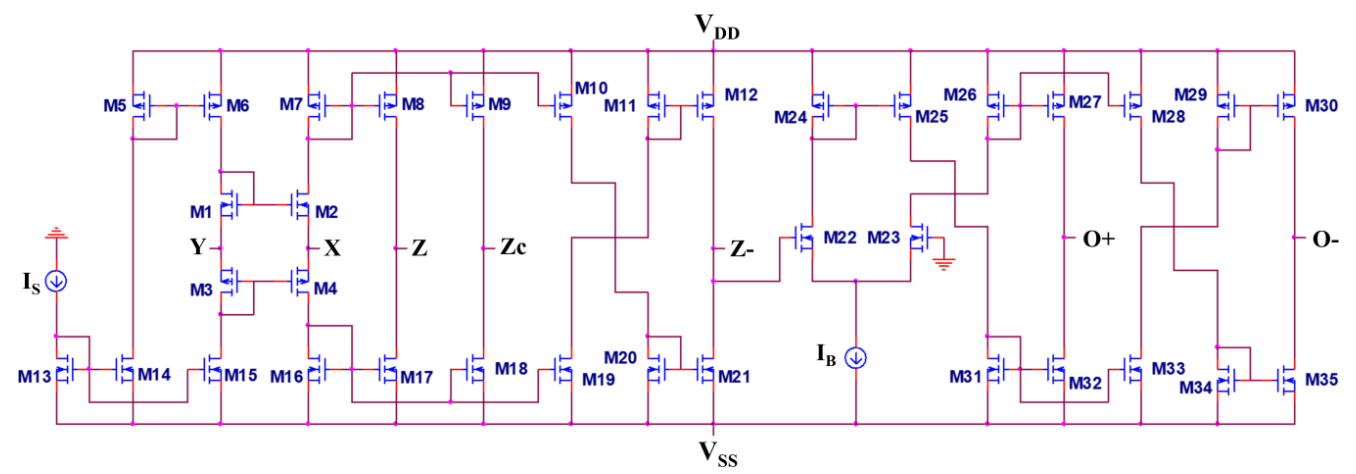

Figure 2 Internal structure of MO-CCCCTA utilizing CMOS transistors [27,31].

\section{Basic concept of the designed circuit}

The fundamental idea for devising the squaring and square-rooting circuits has been introduced at first in Figure 3. When both the switches $S_{1}$ and $S_{2}$ are opened and the MO-CCCCTA is with ideal characteristics, routine circuit analysis offers the following results;

$$
I_{\text {out }}=I_{O-}=-g_{m} V_{z}
$$

and

$$
V_{z}=V_{y}=-I_{\text {in }} R_{x}
$$

therefore,

$I_{\text {out }}=g_{m} R_{x} I_{\text {in }}=\sqrt{\frac{(W / L)_{22,23} I_{B}}{8(W / L)_{1,2} I_{S}}} I_{\text {in }}$

It is obvious from Eq. (5) that the circuit operates as a current amplifier. The magnitude of the output current $\left(I_{\text {out }}\right)$ can be adjusted easily by controlling the bias current $I_{B}$ and/or $I_{S}$. This basic idea has been used to realize the squaring and square-rooting circuits. The implementations of both the squaring and square-rooting circuits will be represented in the succeeding sections. 


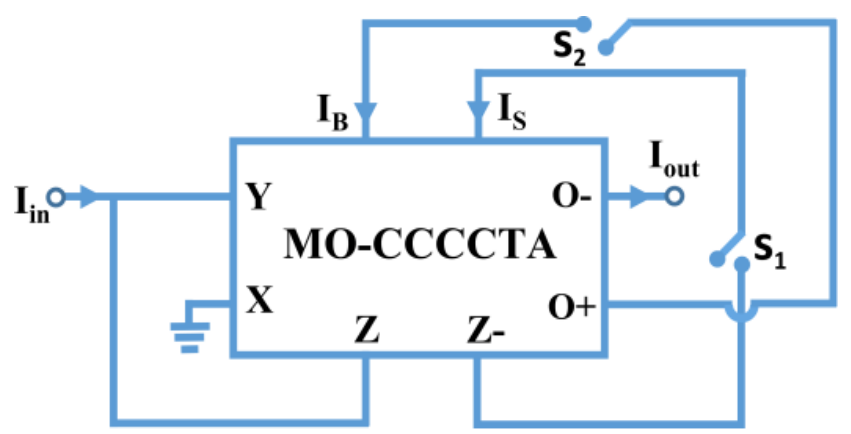

Figure 3 Basic diagram of the designed circuit.

\section{Proposed square-rooting circuit}

Eq. (5) clearly indicates that if $I_{\text {in }}$ is put in for $I_{S}$, i.e., closing switch $S_{I}$ and opening switch $S_{2}$ in Figure 3, the output current $\left(I_{\text {out }}\right)$ will be proportional to the square root of the input current $\left(I_{\text {in }}\right)$. Its magnitude can be adjusted by tuning the bias current $I_{B}$. The expression for the output current of the proposed square-rooting circuit has been given in Eq. (6);

$$
I_{\text {out }}=k \sqrt{I_{B}} \sqrt{I_{\text {in }}} ; k=\left\{\left(\frac{W}{L}\right)_{22,23} / 8\left(\frac{W}{L}\right)_{1,2}\right\}^{1 / 2}
$$

\section{Proposed squaring circuit}

It is also evident from Eq. (5) that a squarer can be realized by putting $I_{\text {out }}$ for $I_{B}$, i.e., opening switch $S_{1}$ and closing switch $S_{2}$ in the circuit of Figure 3. The squarer circuit provides the following output;

$$
I_{\text {out }}=\frac{k^{2}}{I_{S}} I_{\text {in }}^{2}
$$

Clearly from Eq. (7), the output current $\left(I_{\text {out }}\right)$ is directly proportional to the square of the input current $\left(I_{i n}\right)$. Its magnitude can be adjusted by controlling the bias current $I_{S}$. Note that the circuit operates only for the positive input. In order to get a squaring output for the bidirectional current input, another configuration has been put forward and displayed in Figure 4. A routine analysis shows that the circuit of Figure 4 yields the output as follows;

$$
I_{\text {out }}=I_{O 1-}+I_{O 2-}
$$

where

$$
I_{O \mathrm{l}-}=\left\{\begin{array}{c}
k^{2} \frac{I_{i n}{ }^{2}}{I_{S 1}}, \quad I_{i n}>0 \\
0, \quad I_{i n} \leq 0
\end{array}\right.
$$

and

$I_{O 2-}=\left\{\begin{array}{l}k^{2} \frac{I_{i n}^{2}}{I_{S 2}}, \quad I_{i n}<0 \\ 0, \quad I_{i n} \geq 0\end{array}\right.$ 
It is clear that the MO-CCCCTA-1 and the MO-CCCCTA-2 alternate for the positive and negative cycle of input current if $I_{S 1}=I_{S 2}=I_{S}$. The final output for the full input cycle is then obtained as;

$$
I_{\text {out }}=k^{2} \frac{I_{\text {in }}^{2}}{I_{S}}
$$

Evidently, the circuit of Figure 4 is a true 4-quadrant squarer. However, it is gained at the expense of 1 extra MO-CCCCTA.

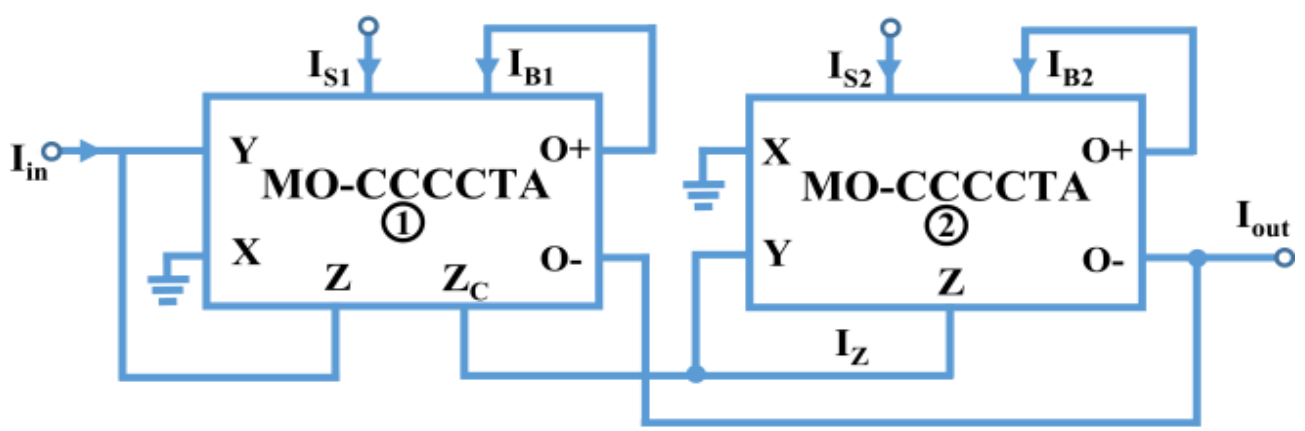

Figure 4 The completed current-mode squarer.

\section{Non-ideality effects}

The analysis in the preceding section is built on the ideal characteristics of the MO-CCCCTA. Practically, the reported circuits are deviated from their ideal performance due to the voltage/current gain errors and parasitic elements in MO-CCCCTA. Considering the voltage/current gain errors, the terminal relationships of MO-CCCCTA can be described as follows;

$$
I_{y}=0, V_{x}=\beta V_{y}+I_{x} R_{x}, I_{z}=\alpha_{p} I_{x}, I_{z c}=\alpha_{p c} I_{x}, I_{z-}=-\alpha_{n} I_{x}, I_{O+}=\gamma_{p} g_{m} V_{z}, \text { and } I_{O-}=-\gamma_{n} g_{m} V_{z}
$$

where $\alpha_{p}$ is the current transfer error from $\mathrm{X}$ terminal to $\mathrm{Z}$ terminal, $\alpha_{p c}$ is the current transfer error from $\mathrm{X}$ terminal to $\mathrm{Z}_{\mathrm{C}}$ terminal, $\alpha_{n}$ is the current transfer error from $\mathrm{X}$ terminal to $\mathrm{Z}$-terminal, $\beta$ is the voltage transfer error from $\mathrm{X}$ terminal to $\mathrm{Y}$ terminal, $\gamma_{p}$ is the current transfer error from $\mathrm{X}$ terminal to $\mathrm{O}+$ terminal, and $\gamma_{n}$ is the current transfer error from $\mathrm{X}$ terminal to O-terminal.

In addition, like any other active device, a practical MO-CCCCTA shows various terminals parasitic. Figure 5 illustrates the well-established parasitic model of MO-CCCCTA [32]. A parasitic resistor $R_{X}$ appears in series at $\mathrm{X}$ terminal, parasitic impedances in the form of $R_{Y} \| C_{Y}$ appears at $\mathrm{Y}$ terminal, $R_{Z} \| C_{Z}$ appears at $\mathrm{Z}$ terminal, $R_{Z-} \| C_{Z_{-}}$appears at $\mathrm{Z}-$ terminal, $R_{O_{+}} \| C_{O_{+}}$appears at $\mathrm{O}+$ terminal and $R_{O_{-}} \| C_{O_{-}}$appears at $\mathrm{O}-$ terminal. All the parasitic resistances are of high values, while the capacitances are of very low values. Taking the terminals parasitic of the MO-CCCCTAs into account and considering the gain errors stated in Eq. (12), the square-rooting circuit yields the following output;

$I_{\text {out }}=\left(\frac{k \gamma_{n}}{\beta}\right) \sqrt{\frac{I_{B}}{\alpha_{p} \alpha_{n}}} \cdot\left[\frac{\sqrt{I_{\text {in }}}}{\sqrt{\left(1-b-\frac{s}{\omega^{\prime}}\right)\left(1+c+\frac{s}{\omega^{\prime \prime}}\right)}}\right]$

Similarly, the output current $\left(I_{\text {out }}\right)$ of the basic squaring circuit is found as given in Eq. (14); 


$$
I_{\text {out }}=\frac{\gamma_{p} \gamma_{n}}{I_{S}}\left(\frac{k}{\beta \alpha_{p}}\right)^{2}\left[\frac{\left(I_{\text {in }}\right)^{2}}{\left(1-b-\frac{s}{\omega^{\prime}}\right)^{2}\left(1+c+\frac{s}{\omega^{\prime \prime}}\right)}\right]
$$

Meanwhile, the squarer in Figure 4 reflects the following output;

$$
I_{\text {out }}=\left\{\begin{array}{l}
\frac{\gamma_{p 1} \gamma_{n 1}}{I_{S 1}}\left(\frac{k}{\alpha_{p 1} \beta_{1}}\right)^{2}\left[\frac{\left(I_{i n}\right)^{2}}{\left.\left(1-b_{1}-\frac{s}{\omega_{1}^{\prime}}\right)^{2}\left(1+c_{1}+\frac{s}{\omega_{1}^{\prime \prime}}\right)\right] \text { for } I_{\text {in }}>0}\right. \\
\frac{\gamma_{p 2} \gamma_{n 2}}{I_{S 2}}\left(\frac{k \alpha_{p c 1}}{\alpha_{p 1} \alpha_{p 2} \beta_{2}}\right)^{2}\left[\frac{\left(I_{i n}\right)^{2}}{\left[1-b_{1}-\frac{s}{\omega_{1}^{\prime}}\right]^{2}\left(1+c_{2}+\frac{s}{\omega_{2}^{\prime \prime}}\right)\left[1-d-\frac{\left\{1+\frac{C_{Z_{1} 1}}{\left(C_{\left.\gamma_{2}+C_{z 2}\right)}\right.}\right)}{\omega_{2}^{\prime}}\right]}\right] \text { for } I_{i n}<0
\end{array}\right.
$$

where $b=\frac{R_{X}\left(R_{Y}+R_{Z}\right)}{\alpha_{p} \beta R_{Y} R_{Z}}, c=\frac{R_{L}}{R_{O-}}, d=\left(\frac{1}{R_{Y 2}}+\frac{1}{R_{Z 2}}+\frac{1}{R_{Z C 1}}\right) \frac{R_{X 1}}{\alpha_{p 2} \beta_{2}}, \omega^{\prime}=\frac{\alpha_{p} \beta}{R_{X}\left(C_{Y}+C_{Z}\right)}$, and $\omega^{\prime \prime}=\frac{1}{R_{L} C_{0-}} ; R_{L}$ is the load resistor and the suffix 1 represents the values of the parameters for block 1 (similarly for suffix 2). It is noted from Eqs. (13) - (15) that the non-idealities of the MO-CCCCTAs will cause minor changes in the transfer current gains. Moreover, the output currents may slightly depend on temperature, as the nonideal tracking errors depend on temperature slightly. However, these deviations can be easily compensated by balancing the values of $I_{B}$ and $I_{S}$ for the square-rooting and squaring circuit, respectively. It is also noted that the useful frequency range $(\omega)$ of the proposed circuits are limited by the extra poles $\omega^{\prime}, \omega^{\prime \prime}, \omega_{2}{ }^{\prime}$ and $\omega_{2}{ }^{\prime \prime}$ which become effective at very high frequencies. Therefore, in order to minimize the influence of the MO-CCCCTAs' parasitics, the proper operation frequency should restrict to the following conditions [21];

$\omega \leq 0.1 \omega^{\prime} ; 0.1 \omega^{\prime \prime} ; 0.1 \omega_{2}^{\prime} ;$ and $0.1 \omega_{2}^{\prime \prime}$

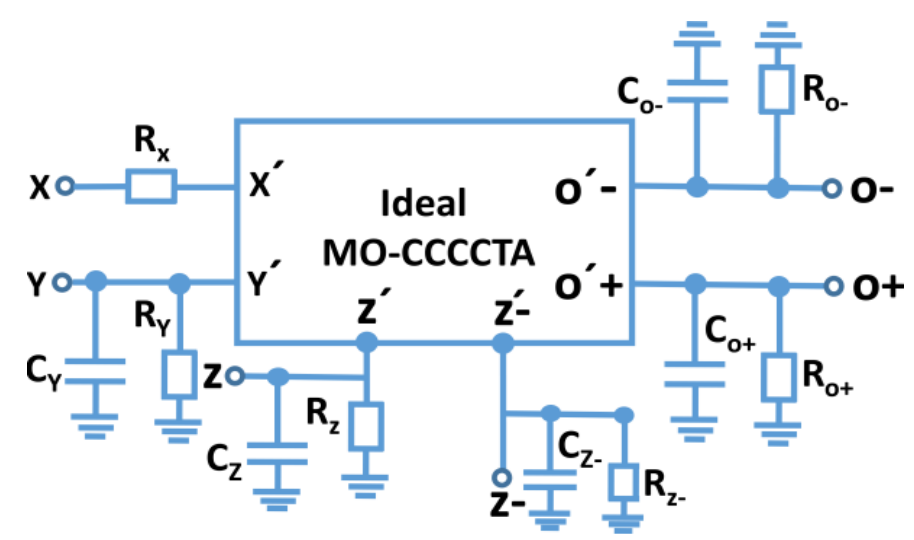

Figure 5 Parasitic model of MO-CCCCTA [32]. 


\section{Simulation results}

To confirm the theoretical predictions, the designed circuits were simulated by Cadence PSPICE program. In order to fulfill the MO-CCCCTA active device in simulations, it was realized by the schematic CMOS structure given in Figure 2 with the TSMC $0.18 \mu \mathrm{m}$ CMOS model parameters. All of the reported circuits are powered by $\pm 0.9 \mathrm{~V}$ supplies. The dimensions of the MOS transistors utilized in the MO-CCCCTA architecture are presented in Table 1. Firstly, the proposed square-rooting circuit has been simulated to show its workability. Figure $\mathbf{6}$ depicts the dc transfer characteristic of the reported square-rooter when the input current $I_{\text {in }}$ is swept from 0 to $300 \mu \mathrm{A}$ along with the variation in bias current $I_{B}$ from 100 to $200 \mu \mathrm{A}$ at $50 \mu \mathrm{A}$ per step. Similarly, Figure 7 presents the de transfer characteristics of the designed square-rooter when the bias current $I_{B}$ is swept from 0 to $300 \mu \mathrm{A}$ against the vary in input current $I_{\text {in }}$ from 50 to $100 \mu \mathrm{A}$ at $25 \mu \mathrm{A}$ per step. In these figures, the simulated results are compared with the theoretical values and they are found to be in close agreement over the entire operating range. Table 2 presents the relative errors of the results in Figure 6. The same for the results of Figure 7 is depicted in Table 3.

Figure 8 displays the transient response when a $10 \mathrm{MHz}, 150 \mu \mathrm{A}$ triangular signal is applied to the input of the square rooter for different values of bias current $I_{B}(100,150$ and $200 \mu \mathrm{A})$. The same for a 10 $\mathrm{MHz}, 150 \mu \mathrm{A}$ sinusoidal signal is shown in Figure 9. The frequency response of the proposed square rooter is further investigated and the obtained result is given in Figure 10, from which the $-3 \mathrm{~dB}$ bandwidth is found to be about $445.63 \mathrm{MHz}$.

Table 1 The dimensions of the MOS transistors utilized in the MO-CCCCTA architecture [27].

\begin{tabular}{cc}
\hline Transistor & $\mathbf{W} / \mathbf{L}(\boldsymbol{\mu m} / \boldsymbol{\mu m})$ \\
\hline M1, M2 & $7 / 0.35$ \\
M3, M4 & $28 / 0.35$ \\
M5-M12 & $16 / 0.5$ \\
M13-M21 & $5 / 0.5$ \\
M22, M23 & $10 / 0.5$ \\
M24-M30 & $25 / 0.8$ \\
M31-M35 & $6.2 / 0.8$ \\
\hline
\end{tabular}

Table 2 Theoretical and simulated output currents with percentage errors for the results in Figure 6.

\begin{tabular}{ccccccccccc}
\hline \multirow{2}{*}{$\begin{array}{c}\mathbf{I}_{\mathbf{I N}} \\
(\boldsymbol{\mu} \mathbf{A})\end{array}$} & \multicolumn{3}{c}{$\mathbf{I}_{\mathbf{B}}=\mathbf{1 0 0} \boldsymbol{\mu} \mathbf{A}$} & \multicolumn{3}{c}{$\mathbf{I}_{\mathbf{B}}=\mathbf{1 5 0} \boldsymbol{\mu} \mathbf{A}$} & \multicolumn{3}{c}{$\mathbf{I}_{\mathbf{B}}=\mathbf{2 0 0} \boldsymbol{\mu \mathbf { A }}$} \\
\cline { 2 - 10 } & Theoretical & Simulated & $\begin{array}{c}\mathbf{\%} \\
\text { Error }\end{array}$ & Theoretical & Simulated & $\begin{array}{c}\text { \% } \\
\text { Error }\end{array}$ & Theoretical & Simulated & $\begin{array}{c}\text { \% } \\
\text { Error }\end{array}$ \\
\hline 0 & 0 & 0.134 & - & 0 & 0.157 & - & 0 & 0.208 & - \\
50 & 25 & 25.245 & -0.98 & 30.618 & 30.913 & -0.96 & 35.355 & 35.666 & -0.88 \\
100 & 35.355 & 35.609 & -0.72 & 43.301 & 43.574 & -0.63 & 50 & 49.925 & 0.15 \\
150 & 43.301 & 43.219 & 0.19 & 53.033 & 52.942 & 0.17 & 61.237 & 61.072 & 0.27 \\
200 & 50 & 49.785 & 0.43 & 61.237 & 60.776 & 0.75 & 70.711 & 69.926 & 1.11 \\
250 & 55.901 & 55.298 & 1.08 & 68.465 & 67.855 & 0.89 & 79.057 & 78.219 & 1.06 \\
300 & 61.237 & 60.6 & 1.04 & 75 & 74.175 & 1.1 & 86.603 & 85.633 & 1.12 \\
\hline
\end{tabular}




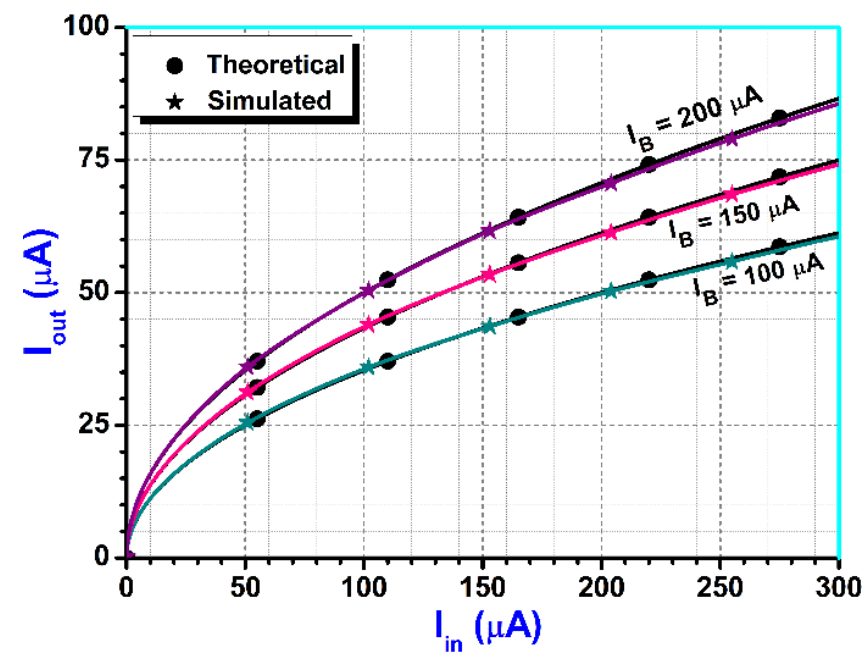

Figure 6 The dc transfer characteristic of the square rooter: Variation of output current $I_{\text {out }}$ against input current $I_{i n}$.

Table 3 Theoretical and simulated output currents with percentage errors for the results in Figure 7.

\begin{tabular}{|c|c|c|c|c|c|c|c|c|c|}
\hline \multirow{2}{*}{$\begin{array}{c}\mathbf{I}_{\mathbf{B}} \\
(\boldsymbol{\mu} \mathbf{A})\end{array}$} & \multicolumn{3}{|c|}{$\mathbf{I}_{\mathrm{in}}=50 \boldsymbol{\mu} \mathrm{A}$} & \multicolumn{3}{|c|}{$I_{\text {in }}=75 \mu \mathrm{A}$} & \multicolumn{3}{|c|}{$I_{\text {in }}=100 \mu \mathrm{A}$} \\
\hline & Theoretical & Simulated & \% Error & Theoretical & Simulated & \% Error & Theoretical & Simulated & \% Error \\
\hline 0 & 0 & 0 & 0 & 0 & 0 & 0 & 0 & 0 & 0 \\
\hline 50 & 17.677 & 17.871 & -1.1 & 21.651 & 21.855 & -0.94 & 25 & 25.272 & -1.09 \\
\hline 100 & 25 & 25.245 & -0.98 & 30.619 & 30.885 & -0.87 & 35.354 & 35.610 & -0.72 \\
\hline 150 & 30.618 & 30.912 & -0.96 & 37.5 & 37.8 & -0.8 & 43.301 & 43.574 & -0.63 \\
\hline 200 & 35.356 & 35.667 & -0.88 & 43.301 & 43.339 & -0.09 & 50 & 49.925 & 0.15 \\
\hline 250 & 39.528 & 39.951 & -1.07 & 48.412 & 48.567 & -0.32 & 55.901 & 55.589 & 0.56 \\
\hline 300 & 43.301 & 43.786 & -1.12 & 53.033 & 53.187 & -0.29 & 61.237 & 60.717 & 0.85 \\
\hline
\end{tabular}

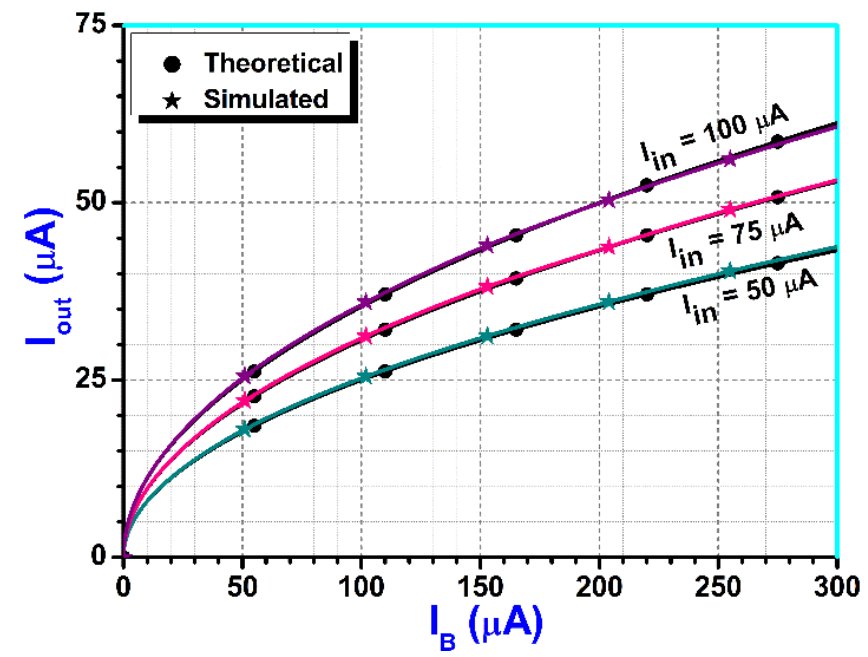

Figure 7 The de transfer characteristic of the square rooter: Variation of output current $I_{\text {out }}$ against bias current $I_{B}$. 


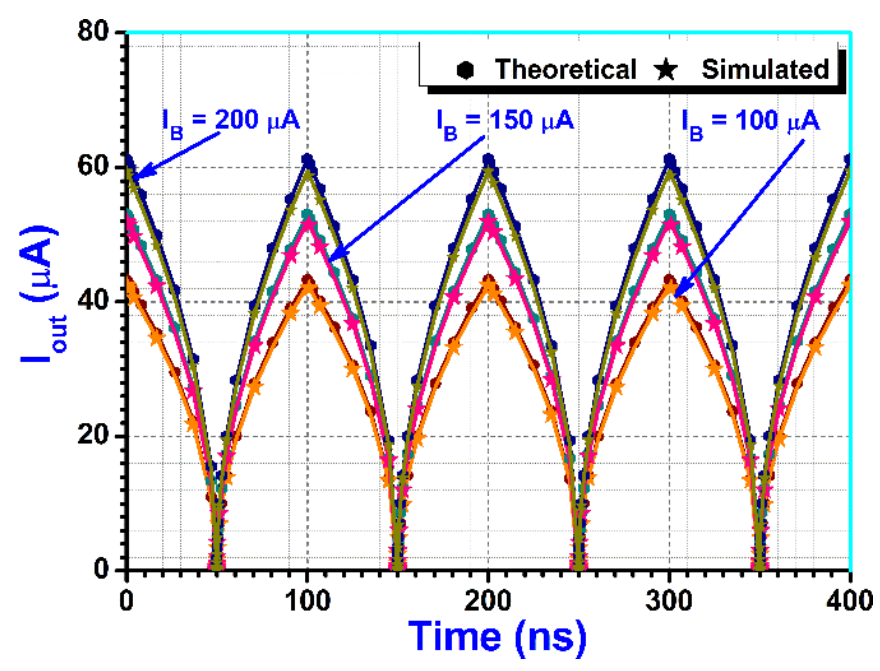

Figure 8 Transient response of the square rooter for triangular input.

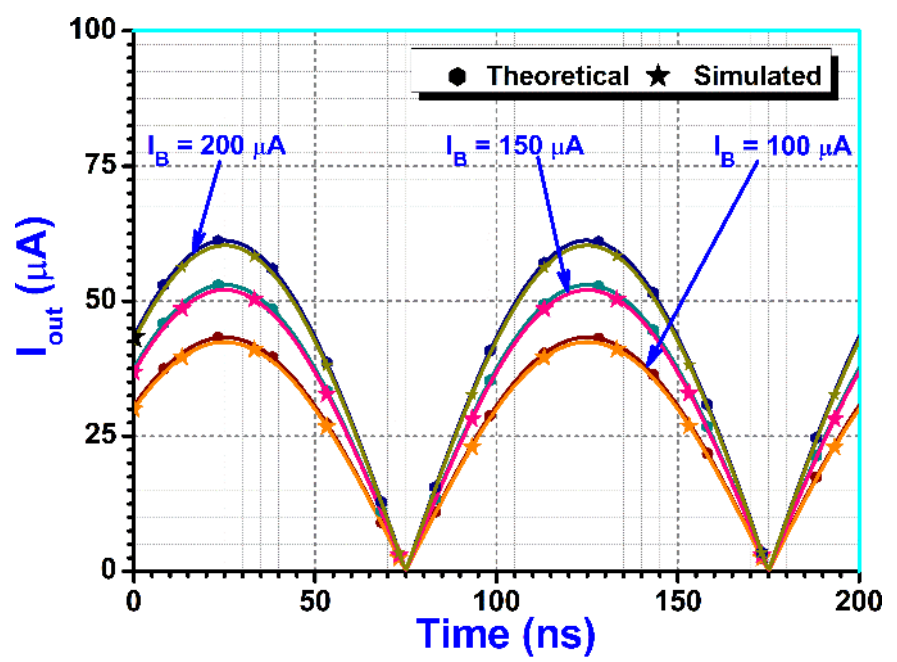

Figure 9 Transient response of the square rooter for sinusoidal input.

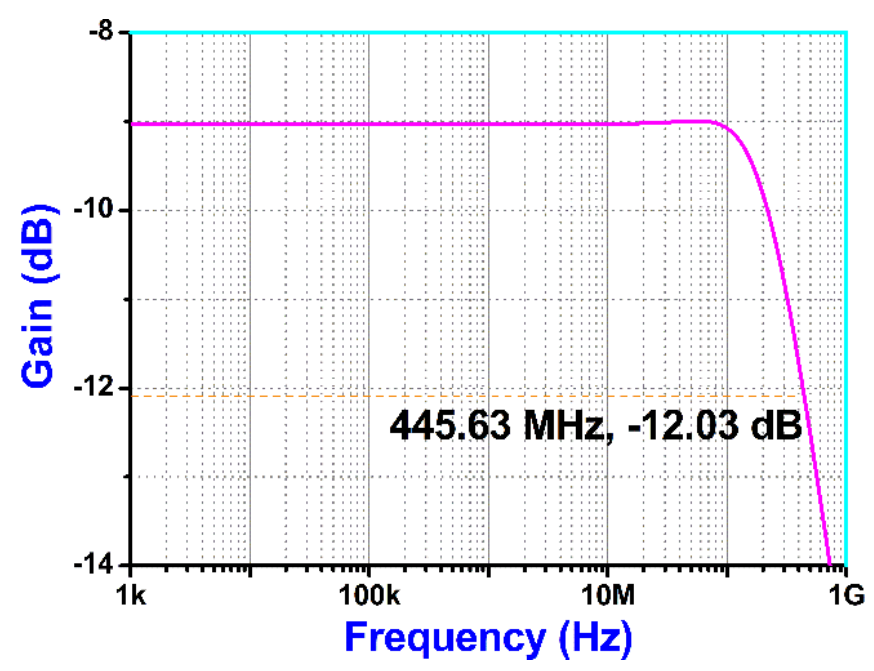

Figure 10 Frequency response characteristic of the designed square-rooter. 
The simulation results of the proposed squaring circuits have been given in Figures 11 - 16. The variation of output current $I_{\text {out }}$ of the squaring circuits reported in Figures $\mathbf{3}$ and $\mathbf{4}$ against the variation of input current $I_{i n}$ for different values of bias current $I_{S}$ are demonstrated in Figures 11 and 12, respectively. For both configurations, the input current $I_{\text {in }}$ is varied from -300 to $300 \mu \mathrm{A}$ and the bias current $I_{S}$ is swept from 50 to $100 \mu \mathrm{A}$ with increments of $25 \mu \mathrm{A}$. Evidently, the squarer of Figure 4 is a true 4quadrant squarer while the squarer of Figure 3 operates only for positive input. This is in accordance with the prediction made earlier in section 'Proposed squaring circuit'. The relative error between the theoretical and simulation outputs for the circuit of Figure 4 is presented in Table 4.

Table 4 Theoretical and simulated output currents with percentage errors for the squarer in Figure 4.

\begin{tabular}{cccccccccc}
\hline \multirow{2}{\mathbf{I}_{\mathbf{IN}}}{\begin{tabular}{c}
$\boldsymbol{\mu} \mathbf{A})$ \\
\cline { 2 - 7 }
\end{tabular}} & Theoretical & Simulated & \% Error & Theoretical & Simulated & \% Error & Theoretical & Simulated & \% Error \\
\hline-300 & 225 & 229.815 & -2.14 & 150 & 152.505 & -1.67 & 112.5 & 115.178 & -2.38 \\
-250 & 156.25 & 159.875 & -2.32 & 104.167 & 106.063 & -1.82 & 78.125 & 79.953 & -2.34 \\
-200 & 100 & 102.35 & -2.35 & 66.667 & 67.32 & -0.98 & 50 & 51.135 & -2.27 \\
-150 & 56.25 & 56.959 & -1.26 & 37.5 & 37.928 & -1.14 & 28.125 & 28.73 & -2.15 \\
-100 & 25 & 25.298 & -1.19 & 16.667 & 16.889 & -1.33 & 12.5 & 12.788 & -2.304 \\
-50 & 6.25 & 6.329 & -1.26 & 4.167 & 4.254 & -2.09 & 3.125 & 3.199 & -2.37 \\
0 & 0 & -0.192 & - & 0 & -0.237 & - & 0 & 0.464 & - \\
50 & 6.25 & 6.314 & -1.02 & 4.167 & 4.204 & -0.89 & 3.125 & 3.193 & -2.18 \\
100 & 25 & 25.218 & -0.87 & 16.667 & 16.77 & -0.62 & 12.5 & 12.688 & -1.50 \\
150 & 56.25 & 56.576 & -0.58 & 37.5 & 37.672 & -0.46 & 28.125 & 28.468 & -1.22 \\
200 & 100 & 100.35 & -0.35 & 66.667 & 66.82 & -0.23 & 50 & 50.275 & -0.55 \\
250 & 156.25 & 155.125 & 0.72 & 104.167 & 105.052 & -0.85 & 78.125 & 79.25 & -1.44 \\
300 & 225 & 222.39 & 1.16 & 150 & 151.56 & -1.04 & 112.5 & 114.514 & -1.79 \\
\hline
\end{tabular}

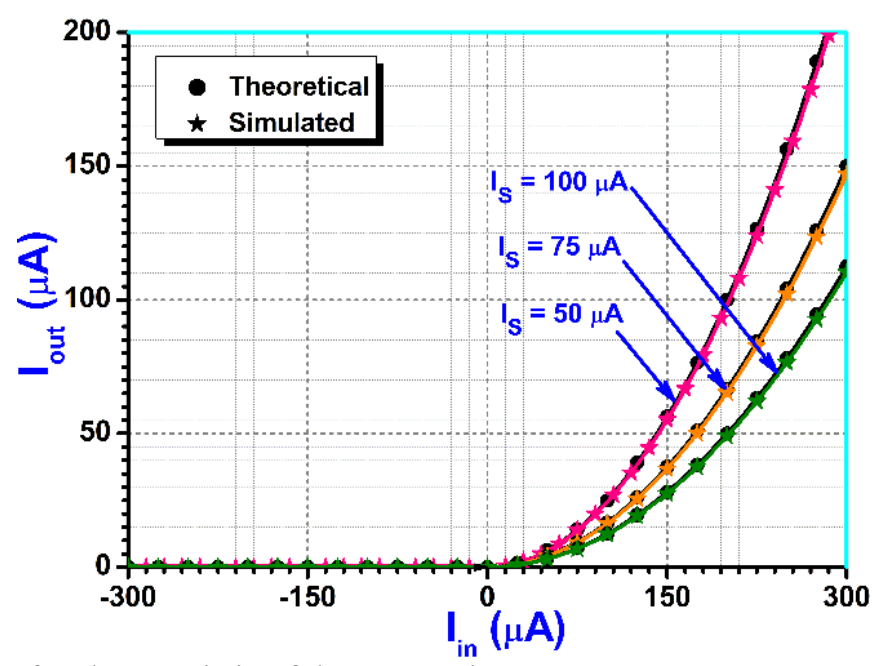

Figure 11 The de transfer characteristic of the squarer in Figure 3. 


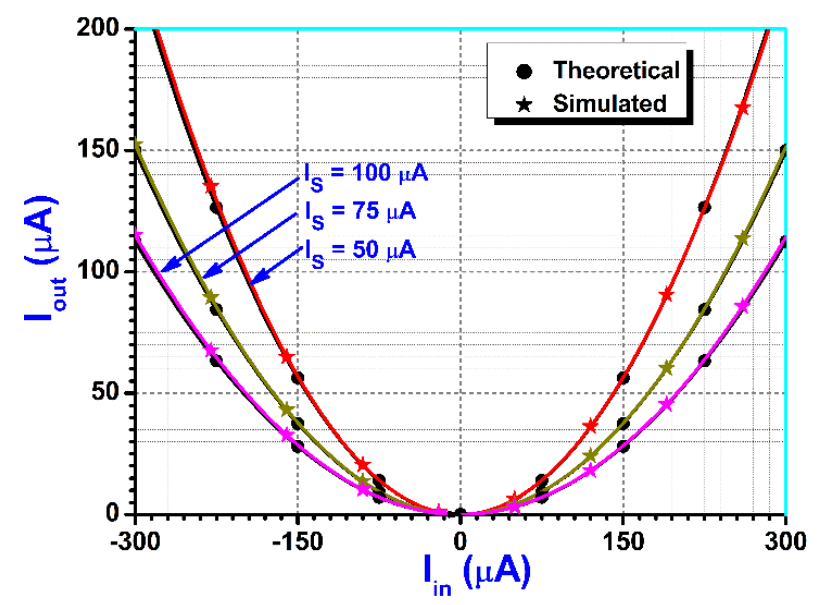

Figure 12 The dc transfer characteristic of the squarer in Figure 4.

The gain performance for the squarer in Figure 4 is further investigated and the result is plotted in Figure 13. This is obtained by varying the bias current $I_{S}$ from 0 to $100 \mu \mathrm{A}$ and sweeping the input current $I_{i n}$ from 150 to $250 \mu \mathrm{A}$ with $50 \mu \mathrm{A}$ increment. Figure 14 shows the frequency response characteristics of the given 4-quadrant squaring circuit, from which the $-3 \mathrm{~dB}$ bandwidth is calculated as about $61.15 \mathrm{MHz}$.

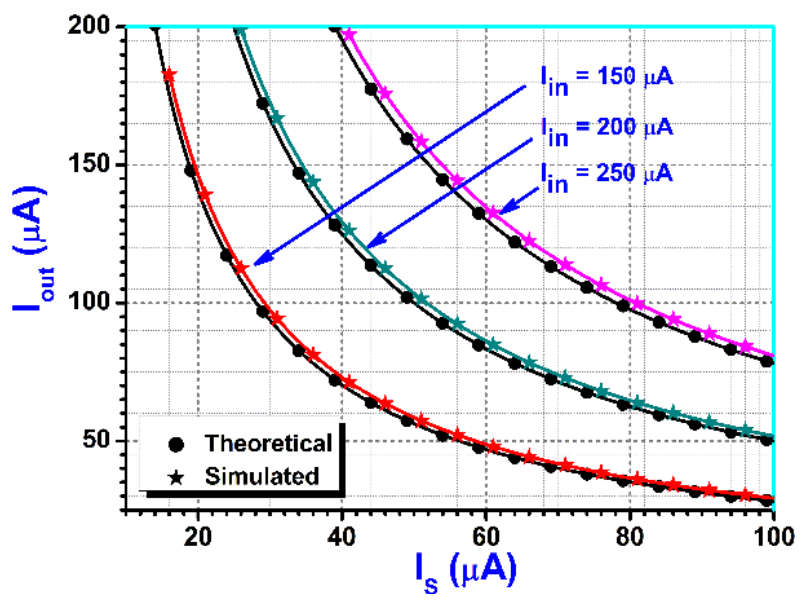

Figure 13 Variation of $I_{\text {out }}$ against $I_{S}$ for the squarer in Figure 4.

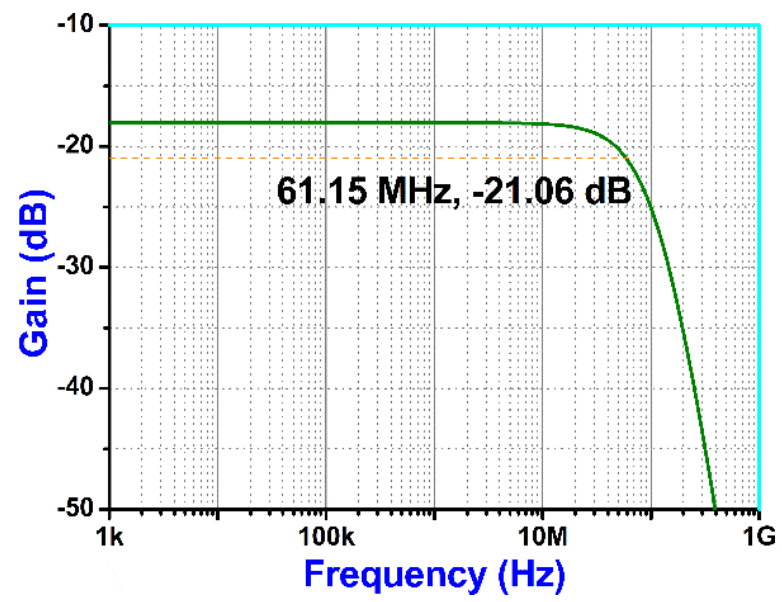

Figure 14 Frequency response characteristic for the squarer in Figure 4. 
Figure 15 plots the simulated transient response for the current squarer given in Figure 4, in which the input current $I_{\text {in }}$ is a $10 \mathrm{MHz}, 300 \mu \mathrm{A}$ triangular signal and the bias current $I_{S}$ is swept from $50 \mu \mathrm{A}$ to $100 \mu \mathrm{A}$ with $25 \mu \mathrm{A}$ increment. In the same manner, the output waveforms generated from the current squarer given in Figure 4 for a $10 \mathrm{MHz}, 300 \mu \mathrm{A}$ sinusoidal signal is shown in Figure 16.

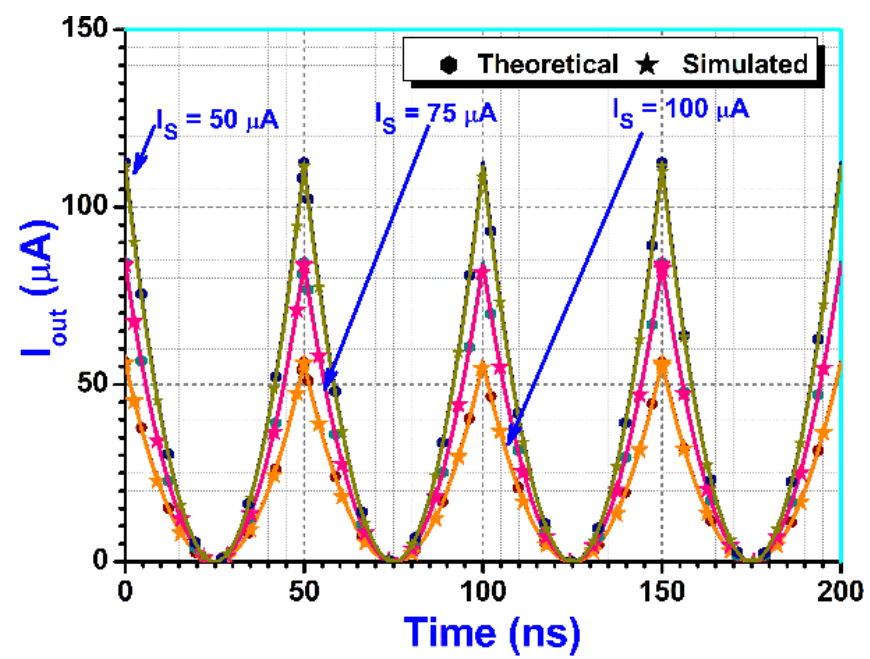

Figure 15 Transient response of the squarer in Figure 4 for triangular input.

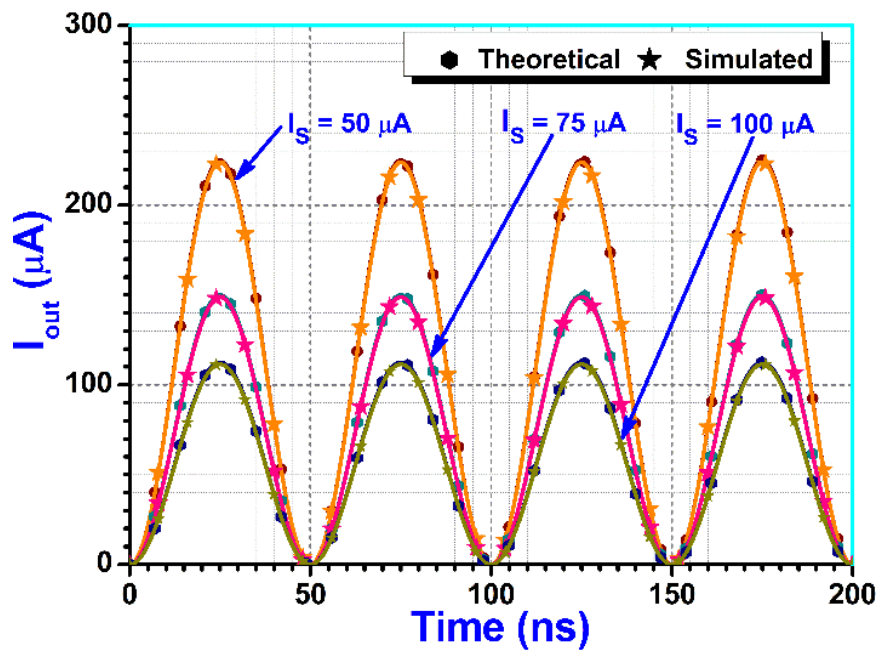

Figure 16 Transient response of the squarer in Figure 4 for sinusoidal input.

The effects of temperature variation on the output waveforms of the designed square-rooter and current squarer have also been examined by fixing the ambient temperature at 25,50 and $100{ }^{\circ} \mathrm{C}$. The simulated responses when $I_{\text {in }}$ is a $10 \mathrm{MHz}, 300 \mu \mathrm{A}$ triangular signal are presented in Figures 17 and 18, respectively. They confirmed that the output performances are insensitive to the temperature variations (maximum deviation is $4.6 \%$ for the squaring circuit for temperature variation from 25 to $100{ }^{\circ} \mathrm{C}$, whereas it is just $0.8 \%$ for the square-rooting circuit). The average power consumption is found to be $0.17 \mathrm{~mW}$ and $0.326 \mathrm{~mW}$ for the designed square-rooting and 4-quadrant squaring circuit, respectively. 


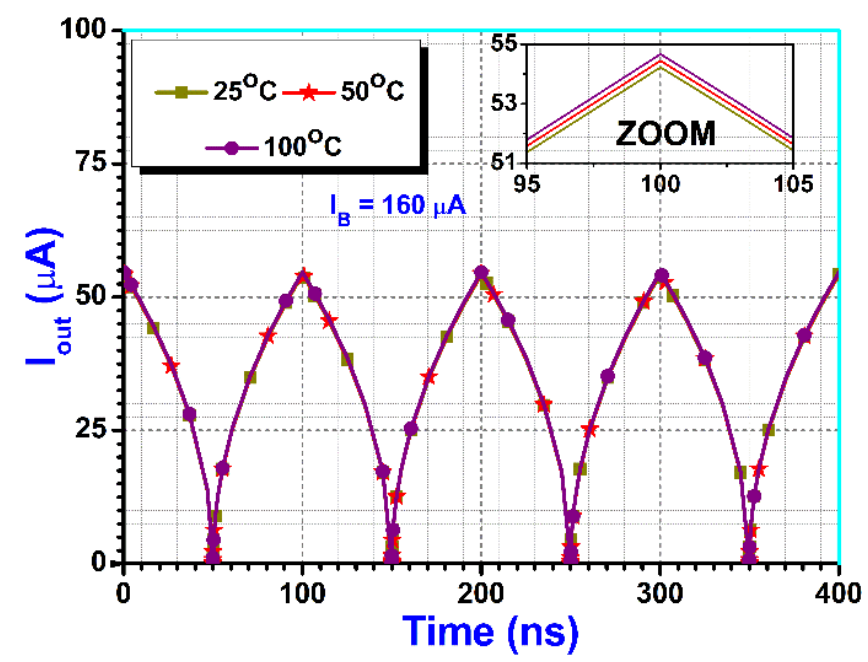

Figure 17 Impact of temperature on output current of the square-rooter.

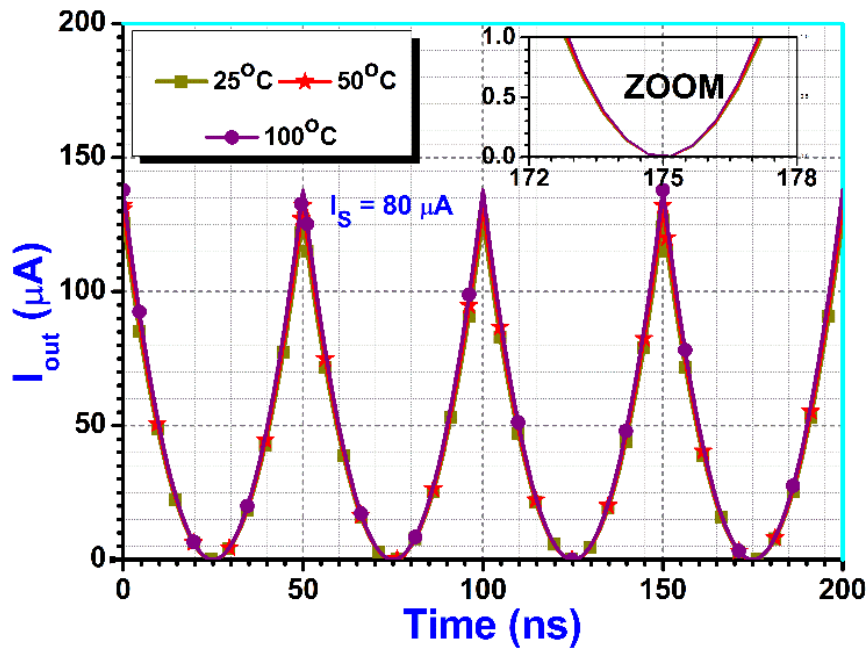

Figure 18 Impact of temperature on output current of the squarer in Figure 4.

To verify the robustness of the designed circuits, Monte-Carlo simulations are carried out for hundred runs considering $\pm 5 \%$ deviation in transconductance and threshold voltage of the MOS transistors utilized in the MO-CCCCTA architecture. The simulation outcomes for the measured bandwidth of the proposed square-rooter and 4-quadrant squarer are presented in Figures 19 and 20 , respectively. Clearly, the $-3 \mathrm{~dB}$ bandwidth of the square-rooter varies within 441.297 and $449.944 \mathrm{MHz}$ with $1.739 \mathrm{MHz}$ standard deviation whereas the same for the designed 4-quadrant squarer varies within 60.375 and $61.972 \mathrm{MHz}$ with $321.304 \mathrm{kHz}$ standard deviation. The results are satisfactory. 


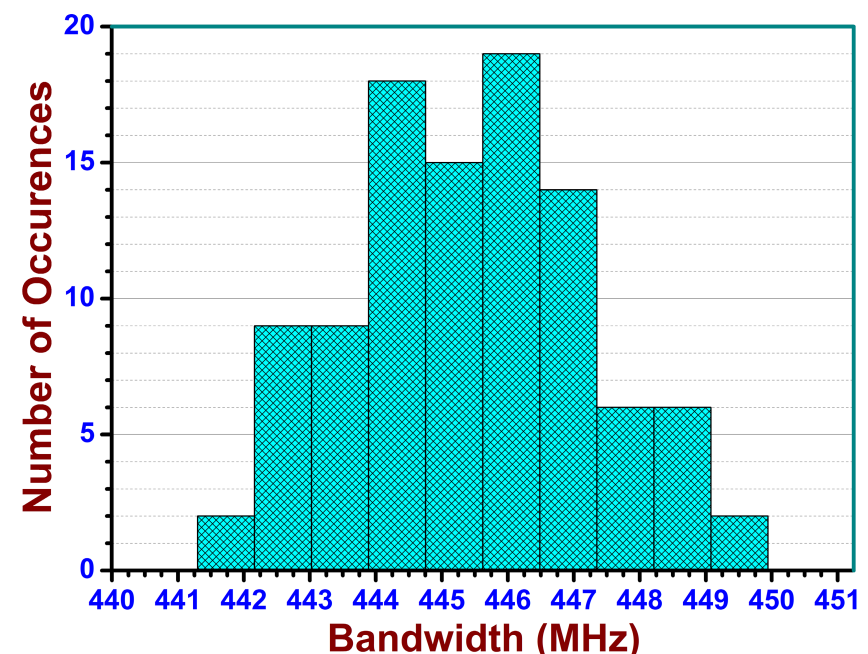

n samples $=100 \quad$ mean $=445.6273 \mathrm{MHz}$ median $=445.6105 \mathrm{MHz}$ $\mathrm{n}$ division $=10 \quad \min =441.2972 \mathrm{MHz} \quad 10$ th $\%$ ile $=443.01 \mathrm{MHz}$ $\sigma=1.7394 \mathrm{MHz} \quad \max =449.9435 \mathrm{MHz} \quad 90$ th $\%$ ile $=447.53 \mathrm{MHz}$

Figure 19 Monte-Carlo simulation outcome for $-3 \mathrm{~dB}$ bandwidth of the proposed square-rooter.

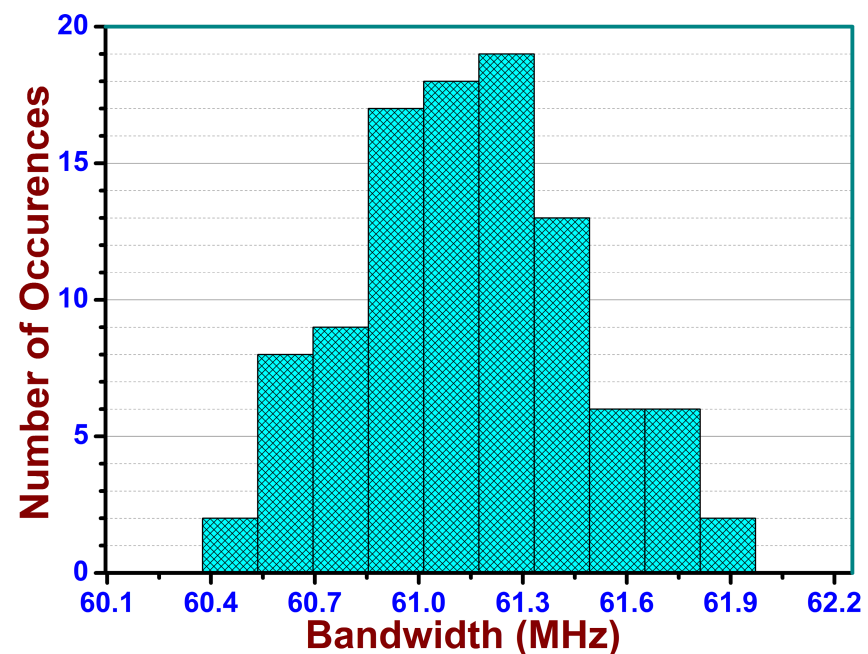

\begin{tabular}{|lrc|}
\hline n samples $=100$ & $\operatorname{mean}=61.14826 \mathrm{MHz}$ & median $=61.14804 \mathrm{MHz}$ \\
n division $=10$ & $\min =60.37546 \mathrm{MHz}$ & 10th \%ile $=60.697 \mathrm{MHz}$ \\
$\sigma=321.304 \mathrm{kHz}$ & $\max =61.97173 \mathrm{MHz}$ & 90th \%ile $=61.607 \mathrm{MHz}$ \\
\hline
\end{tabular}

Figure 20 Monte-Carlo simulation outcome for $-3 \mathrm{~dB}$ bandwidth of the squarer in Figure 4.

\section{Application}

In order to show the applicability of the reported circuits, a 2-input vector summation circuit is discussed. Vector summation circuit is found extensively useful in many fields like communication, instrumentation and fuzzy systems [6]. Generally, the vector summation computing methods use the squaring and square-rooting function. A possible configuration of 2-input vector summation circuit is depicted in Figure 21. Since the designed squaring and square-rooting circuits work with high output impedance, there is no necessity for any intermediate buffer stage. The circuit employs 2 squarer and 1 square-rooter. 


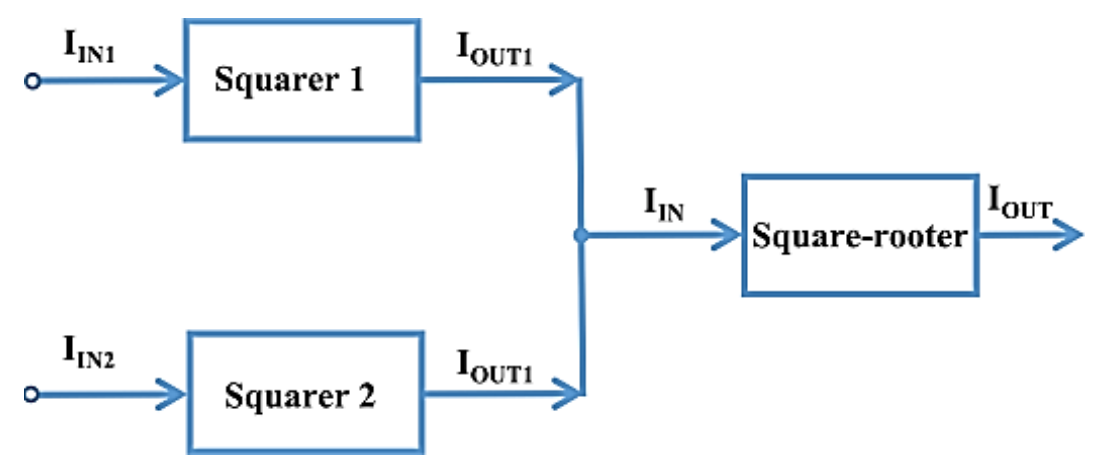

Figure 21 Basic configuration of the 2-input vector summation circuit [6].

The current $I_{i n_{j}}$ has been injected to the $\mathrm{j}^{\text {th }}$ squarer input and then the sum of every single output current $I_{\text {out }_{j}}$ has been applied to the input $I_{\text {in }}$ of the square-rooter. Thus;

$I_{\text {in }}=\sum_{j=1}^{2} I_{\text {out }_{j}}$

Recalling Eqs. (6) and (11), the square-rooter provides the following vector magnitude;

$I_{\text {out }}=k^{2} \sqrt{I_{B} / I_{S}} \sqrt{{I_{i n_{1}}{ }^{2}+I_{i n_{2}}{ }^{2}}^{2}}$

Hence, a 2-input vector summation circuit can be accomplished. Figure 22 demonstrates the simulated results of the 2-input vector summation circuit employing the proposed squaring and squarerooting circuits. In this case, 2 triangular current signals, one with $300 \mu \mathrm{A}_{\mathrm{p}-\mathrm{p}}$ amplitude and $5 \mathrm{MHz}$ frequency and another with $300 \mu \mathrm{A}_{\mathrm{p}-\mathrm{p}}$ amplitude and $10 \mathrm{MHz}$ frequency are fed as the input current. The bias currents are set as $I_{S}=80 \mu \mathrm{A}$ and $I_{B}=200 \mu \mathrm{A}$.

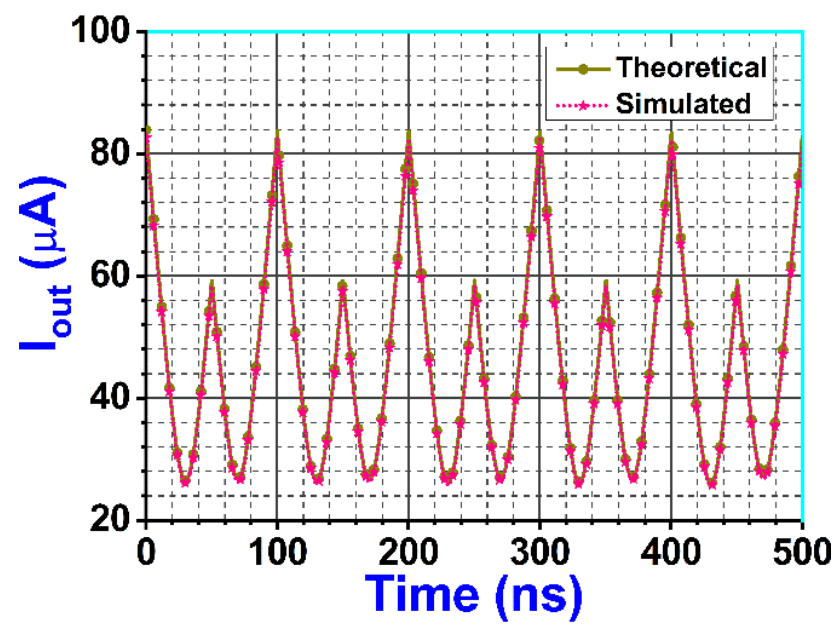

Figure 22 Transient response of the 2-input vector summation circuit. 


\section{Discussion and comparison with existing structures}

A comparison of the designed current-mode square-rooting and squaring circuits with the previously published active building block based square-rooting and squaring circuits has been demonstrated in Tables $\mathbf{5}$ and $\mathbf{6}$, respectively. It is clear that the designed square-rooting circuit uses minimum possible components and consumes least power among the references given in Table $\mathbf{5}$. Although the square-rooters of $[3,16]$ provide better linearity than the proposed structure, they needed a very large power supply. Moreover, the bandwidth of the circuits in [3] is very low, while [16] uses a large number of active building blocks. Though the square-rooter of [22] employs only a single active block similar to the proposed structure, it uses bipolar technology, its output impedance is low and also needed a large power supply. Contrarily, the square-rooter of [15] offers larger bandwidth at the cost of poor linearity and additional power dissipation. Evidently, none of the references mentioned in Table 5 can simultaneously achieve the advantageous features of the proposed square-rooter, i.e., simple architecture, low component count, larger bandwidth, lower power dissipation, electronic tunability, better linearity, insensitivity to temperature drift and availability of high output impedance. Hence, the proposed circuit is strikingly superior to others compared here.

Table 5 Comparison between the suggested and previously reported square-rooting circuits.

\begin{tabular}{|c|c|c|c|c|c|c|c|c|c|}
\hline $\begin{array}{l}\text { Ref. } \\
\text { No./ Year }\end{array}$ & $\begin{array}{l}\text { Number and name } \\
\text { of active block }\end{array}$ & $\begin{array}{l}\text { Number of active/ } \\
\text { passive elements }\end{array}$ & $\begin{array}{c}\text { Output } \\
\text { impedance }\end{array}$ & BW & $\begin{array}{c}\text { Power } \\
\text { consumption } \\
(\mathbf{m W})\end{array}$ & Technology & $\begin{array}{c}\text { Linearity } \\
\text { error }\end{array}$ & $\begin{array}{l}\text { Supply } \\
\text { voltage } \\
\text { (V) }\end{array}$ & $\begin{array}{l}\text { Mode of } \\
\text { operation }\end{array}$ \\
\hline \multirow{2}{*}[3]{$/ 2014$} & $\begin{array}{c}\text { Figure 3 } \\
1 \mathrm{CDBA}, 1 \mathrm{~B}\end{array}$ & $2 \mathrm{M}+1 \mathrm{R}$ & \multirow{2}{*}{ HIGH } & $3.46 \mathrm{MHz}$ & \multirow{2}{*}{ NR } & \multirow{2}{*}{$0.35 \mu \mathrm{m}$} & $<1 \%$ & \multirow{2}{*}{ \pm 5} & \multirow{2}{*}{ Voltage } \\
\hline & $\begin{array}{l}\text { Figure } 4 \\
1 \text { CDBA }\end{array}$ & $4 \mathrm{M}$ & & $2.04 \mathrm{MHz}$ & & & $<2 \%$ & & \\
\hline \multirow{2}{*}[4]{$/ 2007$} & $\begin{array}{l}\text { Figure } 5 \\
2 \text { CCCII }\end{array}$ & $3 \mathrm{R}$ & \multirow{2}{*}{ HIGH } & $60 \mathrm{MHz}$ & 50.4 & \multirow{2}{*}{ BJT } & \multirow{2}{*}{ NR } & \multirow{2}{*}{ \pm 2.5} & Voltage \\
\hline & $\begin{array}{l}\text { Figure } 6 \\
2 \text { CCCII }\end{array}$ & $1 \mathrm{R}$ & & $12 \mathrm{MHz}$ & 5.4 & & & & Current \\
\hline$[5] / 1995$ & 1 CCII, 2 OP-AMP & $2 \mathrm{M}+3 \mathrm{R}$ & LOW & $400 \mathrm{kHz}$ & NR & $\mathrm{BIC}$ & NR & \pm 6 & Voltage \\
\hline$[6] / 2010$ & $2 \mathrm{CCCII}$ & - & $\mathrm{HIGH}$ & $17 \mathrm{MHz}$ & NR & BJT & NR & \pm 1.5 & Current \\
\hline$[7] / 2013$ & 5 OP-AMP & $5 \mathrm{R}, 2 \mathrm{C}$ & LOW & NR & NR & BIC & $1.44 \%$ & \pm 7.5 & Voltage \\
\hline$[8] / 2008$ & 2 OP-AMP & $7 \mathrm{R}$ & LOW & NR & NR & $\mathrm{BIC}$ & NR & \pm 12 & Voltage \\
\hline$[9] / 2017$ & 3 OP-AMP & $2 \mathrm{M}, 6 \mathrm{R}$ & LOW & NR & NR & BIC & NR & \pm 12 & Voltage \\
\hline$[10] / 2009$ & 1 OP-AMP & $6 \mathrm{R}, 1 \mathrm{D}$ & LOW & NR & NR & BIC & $1.34 \%$ & \pm 12 & Voltage \\
\hline$[11] / 1992$ & 1 OP-AMP & $2 \mathrm{M}$ & LOW & NR & NR & $\mathrm{BIC}$ & NR & +5 & $\begin{array}{c}\text { Trans- } \\
\text { impedance }\end{array}$ \\
\hline$[13] / 2017$ & 1 OTRA & $3 \mathrm{M}$ & LOW & NR & NR & $0.18 \mu \mathrm{m}$ & NR & \pm 1.5 & Voltage \\
\hline [14]/1996 & $\begin{array}{c}1 \text { DDCC } \\
- \\
1 \text { V-I converter }\end{array}$ & $2 \mathrm{M}$ & LOW & NR & NR & CD4007 & NR & \pm 7.5 & Voltage \\
\hline$[15] / 2020$ & 1 OTA, 1B & $1 \mathrm{M}$ & $\mathrm{HIGH}$ & $4.42 \mathrm{GHz}$ & 0.442 & $0.18 \mu \mathrm{m}$ & $<2.4 \%$ & \pm 0.9 & Voltage \\
\hline$[16] / 2008$ & 4 OTA & $1 \mathrm{R}$ & $\mathrm{HIGH}$ & NR & NR & BIC & $0.59 \%$ & $\begin{array}{l} \pm 15 \\
\text { (max) }\end{array}$ & $\begin{array}{c}\text { Trans- } \\
\text { conductance }\end{array}$ \\
\hline$[17] / 1993$ & 3 OTA & $2 \mathrm{R}$ & HIGH & NR & NR & BIC & NR & $\begin{array}{c} \pm 15 \\
(\max )\end{array}$ & Voltage \\
\hline$[18] / 2010$ & 4 OTA & - & HIGH & $163 \mathrm{kHz}$ & NR & $\mathrm{BIC}$ & NR & \pm 12 & Current \\
\hline$[21] / 2011$ & $2 \mathrm{CDTA}$ & - & $\mathrm{HIGH}$ & NR & NR & BJT & NR & \pm 3 & Current \\
\hline$[22] / 2011$ & 1 MO-CTTA & - & LOW & NR & 1.83 & BJT & NR & \pm 2 & Current \\
\hline$[23] / 2011$ & 2 MO-CFTA & - & LOW & NR & 1.62 & BJT & NR & \pm 1.5 & Current \\
\hline$[24] / 2009$ & 2 CCCDTA & - & $\mathrm{HIGH}$ & $5.63 \mathrm{MHz}$ & NR & BJT & NR & \pm 1.5 & Current \\
\hline This work & $1 \mathrm{MO}-\mathrm{CCCCTA}$ & - & HIGH & $\begin{array}{l}445.63 \\
\mathrm{MHz}\end{array}$ & 0.17 & $0.18 \mu \mathrm{m}$ & $\leq 1.12 \%$ & \pm 0.9 & Current \\
\hline
\end{tabular}

D-diode, R-resistance, B-buffer, M-MOSFET, NR- not reported, BW-bandwidth, BIC-bipolar IC, 
Table 6 clearly depicts that of all the circuits the reported squarer operates at low supply voltage, dissipates least power and provides better linearity. Although, [3,4,11,13,14,22] employ less number of active block, but $[3,4,11,13,14]$ needed extra active and/or passive components. Besides, they operate either in voltage or in transconductance mode. On the other hand, [22] is based on bipolar technology and provides low output impedance. Though [6,21] employ the same number of active block as the proposed structure, they are based on bipolar technology. Contrarily, the square of [19] offers larger bandwidth at the cost of poor linearity. Moreover, it employed a large number of active building blocks. Hence, the overall performance of the designed squarer is better than any of the circuits mentioned in Table 6, justifying the design proposal.

Table 6 Comparison between the suggested and previously reported squaring circuits.

\begin{tabular}{|c|c|c|c|c|c|c|c|c|c|}
\hline $\begin{array}{l}\text { Ref. } \\
\text { No. / Year }\end{array}$ & $\begin{array}{c}\text { Number and } \\
\text { name of active } \\
\text { block }\end{array}$ & $\begin{array}{c}\text { Number } \\
\text { of active/ } \\
\text { passive elements }\end{array}$ & $\begin{array}{c}\text { Output } \\
\text { impedance }\end{array}$ & BW & $\begin{array}{c}\text { Power } \\
\text { consumption } \\
(\mathrm{mW}) \\
\end{array}$ & $\begin{array}{l}\text { Linearity } \\
\text { error }\end{array}$ & $\begin{array}{l}\text { Supply } \\
\text { voltage } \\
\text { (V) }\end{array}$ & Technology & $\begin{array}{c}\text { Mode of } \\
\text { operation }\end{array}$ \\
\hline [3]/2014 & $1 \mathrm{CDBA}$ & $2 \mathrm{M}, 1 \mathrm{R}$ & HIGH & $30 \mathrm{MHz}$ & NR & $<2.5 \%$ & \pm 5 & $0.35 \mu \mathrm{m}$ & Voltage \\
\hline [5]/1995 & $1 \mathrm{CCII}$ & $2 \mathrm{M}, 1 \mathrm{R}$ & HIGH & $400 \mathrm{kHz}$ & NR & NR & \pm 6 & $\mathrm{BIC}$ & Voltage \\
\hline$[6] / 2010$ & $\begin{array}{l}\text { Figure } 4 \\
2 \text { CCCII } \\
\text { Figure } 5 \\
3 \text { CCCII }\end{array}$ & - & HIGH & NR & NR & NR & \pm 1.5 & BJT & Current \\
\hline [11]/1992 & 1 OP-AMP & $4 \mathrm{M}, 1 \mathrm{R}$ & LOW & NR & NR & NR & +5 & $\mathrm{BIC}$ & $\begin{array}{c}\text { Trans- } \\
\text { conductance }\end{array}$ \\
\hline$[12] / 2018$ & 1 OTRA & $3 \mathrm{M}$ & LOW & NR & 0.746 & NR & \pm 1.5 & $0.5 \mu \mathrm{m}$ & Voltage \\
\hline$[14] / 1996$ & $1 \mathrm{DDCC}$ & $2 \mathrm{M}$ & LOW & NR & NR & NR & \pm 7.5 & $\begin{array}{l}\text { CD4007 } \\
\text { CMOS }\end{array}$ & $\begin{array}{c}\text { Trans- } \\
\text { conductance }\end{array}$ \\
\hline [17]/1993 & 5 OTA & $4 \mathrm{R}$ & HIGH & NR & NR & NR & $\begin{array}{c} \pm 15 \\
(\max )\end{array}$ & BIC & Voltage \\
\hline [19]/2012 & 4 OTA & $1 \mathrm{R}$ & LOW & $110 \mathrm{MHz}$ & NR & $4.8 \%$ & \pm 1.7 & BJT & Current \\
\hline$[20] / 2020$ & $\begin{array}{l}3 \text { OTA, } \\
1 \text { current } \\
\text { squarer }\end{array}$ & - & LOW & NR & 1.2 & NR & \pm 1.5 & $0.25 \mu \mathrm{m}$ & Voltage \\
\hline$[21] / 2011$ & 2 CDTA & - & HIGH & NR & NR & NR & \pm 3 & BJT & Current \\
\hline$[22] / 2011$ & $1 \mathrm{MO}-\mathrm{CTTA}$ & - & LOW & NR & 1.83 & NR & \pm 2 & BJT & Current \\
\hline$[25] / 2009$ & 4 CCCDBAs & - & HIGH & NR & 6.2 & NR & \pm 2 & BJT & Current \\
\hline This work & $\begin{array}{l}2 \text { MO- } \\
\text { CСССТА }\end{array}$ & - & HIGH & $61.15 \mathrm{MHz}$ & 0.326 & $\leq 2.38 \%$ & \pm 0.9 & $0.18 \mu \mathrm{m}$ & Current \\
\hline
\end{tabular}

\section{Conclusions}

This paper proposes the design of simple current-mode squaring and square-rooting circuits employing MO-CCCCTA as an active block. All the designed circuits consist of only MO-CCCCTA active blocks and do not involve any other external components. They offer attractive features for monolithic IC fabrication due to simple architecture, low component count, electronic tunability, insensitivity to ambient temperature variation (maximum deviation is $4.6 \%$ for the squaring circuit for the temperature variation from 25 to $100{ }^{\circ} \mathrm{C}$, whereas it is just $0.8 \%$ for the square-rooting circuit) and high output impendence. Finally, the applicability of the designed circuits is verified through the implementation of a 2-input vector summation circuit. The simulation results generated through PSPICE software using TSMC $0.18 \mu \mathrm{m}$ CMOS process parameters show a good agreement with the theoretical analysis. The maximum linearity error in de transfer characteristic measurement, static power dissipation and the $-3 \mathrm{~dB}$ bandwidth for the derived square-rooter circuit are $1.12 \%, 0.17 \mathrm{~mW}$ and $445.63 \mathrm{MHz}$, respectively. The same for the derived 4-quadrant squaring circuit are $2.38 \%, 0.326 \mathrm{~mW}$ and $61.15 \mathrm{MHz}$, respectively. Therefore, the designed circuits definitely excel in others of the same kind and perform way better effectively. 


\section{Acknowledgements}

The authors gratefully acknowledge FIST-Department of Science and Technology, India and SAPUniversity Grants Commission, India for their continuous financial support to complete the research work.

\section{References}

[1] DR Bhaskar, VK Sharma, M Monis and SMI Rizvi. New current-mode universal biquad filter. Microelectron. J. 1999; 30, 837-9.

[2] S Roy and RR Pal. Electronically tunable third-order quadrature sinusoidal oscillators employing VDCCs and all grounded components. Integration 2021; 76, 99-112.

[3] JK Pathak, AK Singh and R Senani. New squaring and square-rooting circuits using CDBA. Am. J. Electr. Electron. Eng. 2014; 2, 175-9.

[4] K Dejhan and C Netbut. New simple square-rooting circuits based on translinear current conveyors. Int. J. Electron. 2007; 94, 707-23.

[5] SI Liu. Square-rooting and vector summation circuits using current conveyors. IEE Proc. Circ. Dev. Syst. 1995; 142, 223-6.

[6] W Petchakit, A Lorsawatsiri, W Kiranon and C Wongtaychathum. Current-mode squaring, squarerooting and vector summation circuits. AEU Int. J. Electron. Comm. 2010; 64, 443-9.

[7] KC Selvam and S Latha. A simple square rooting circuit based on operational amplifiers (OPAMPs). Eng. Tech. Appl. Sci. Res. 2013; 3, 349-51.

[8] T Kamsri, P Julsereewong and V Riewruja. Simple square-root extractor using op amps. In: Proceedings of the International Conference on Control, Automation and Systems, Seoul, South Korea. 2008, p. 1812-5.

[9] I Chaisayun. A simple and low cost square-rooting circuits employing commercial devices. In: Proceedings of the 2017 International Electrical Engineering Congress, Pattaya, Thailand. 2017.

[10] V Riewruja and $\mathrm{T}$ Kamsri. Square-rooting and absolute function circuits using operational amplifiers. IET Circ. Dev. Syst. 2009; 3, 57-63.

[11] IM Filanovsky and HP Baltes. Simple CMOS analog square-rooting and squaring circuits. IEEE Trans. Circ. Syst. I Fund. Theor. Appl. 1992; 39, 312-5.

[12] BC Nagar and M Ghosh. Squarer and sinusoidal frequency doubler based on single OTRA. In: Proceedings of the $2^{\text {nd }}$ International Conference on Power, Energy and Environment: Towards Smart Technology, Shilong, India. 2018, p. 1-4.

[13] G Aggarwal, H Garg, N Bansal, P Gangwar and R Pandey. Single OTRA based low voltage square root circuit. Int. J. Adv. Res. Innovat. 2017; 5, 431-2.

[14] W Chiu, SI Liu, HW Tsao and JJ Chen. CMOS differential difference current conveyors and their applications. IEE Proc. Circ. Dev. Syst. 1996; 143, 91-6.

[15] A Raj, DR Bhaskar and P Kumar. Two quadrant analog voltage divider and square-root circuits using OTA and MOSFETs. Circ. Syst. Signal Process. 2020; 39, 6358-85.

[16] V Riewruja. Simple square-rooting circuit using OTAs. Electron. Lett. 2008; 44, 1000-2.

[17] TK Sen, A Ray and BN Ray. An arbitrary power law device based on operational transconductance amplifiers. IEEE Trans. Instrum. Meas. 1993; 42, 948-52.

[18] W Tangsrirat, D Prasertsom, T Pukkalanun and W Surakampontorn. Simple current-mode squarerooting circuit with temperature compensation using only OTAs. Int. J. Electr. Eng. Educ. 2010; 47, 23-30.

[19] I Chaisayun and S Maitreechit. An OTA based versatile squarer circuit. In: Proceedings of the $9^{\text {th }}$ International Conference on Electrical Engineering/Electronics, Computer, Telecommunications and Information Technology, Phetchaburi, Thailand. 2012, p. 1-4.

[20] B Boonchu and W Surakampontorn. Dual-output CMOS voltage squarer circuit. In: Proceedings of the $17^{\text {th }}$ International Conference on Electrical Engineering/Electronics, Computer, Telecommunications and Information Technology, Phuket, Thailand. 2020, p. 287-90.

[21] W Tangsrirat, T Pukkalalun, P Monkolwai and W Surakampontron. Simple current-mode analog multiplier, divider, square-rooter and squarer based on CDTAs. AEU Int. J. Electron. Comm. 2011, 65, 198-203.

[22] P Sroymuk and N Pisutthipong. A temperature-insensitive simple current-mode square-root and squarer employing only multiple-output CTTAs. In: Proceedings of the Ninth PSU Engineering Conference, Hat Yai, Thailand. 2011, p. 185-8. 
[23] P Silapan and C Chanapromma. Multiple ouput CFTAs (MO-CFTAs)-based wide-range linearly/electronically controllable current-mode square-rooting circuit. In: Proceedings of the International Symposium on Intelligent Signal Processing and Communications Systems, Chiang Mai, Thailand. 2011, p. 1-4.

[24] A Lahiri and A Chowdhury. Current-mode square rooting circuit using CCCDTA. Int. J. Recent Trends Eng. 2009; 1, 280-2.

[25] S Lawanwisut and M Siripruchyanun. Temperature insensitive/electronically controllable currentmode squarer based on CC-CDBAs. In: Proceedings of the $1^{\text {st }}$ International Conference on Technical Education, Bangkok, Thailand. 2009, p. 225-8.

[26] M Siripruchyanun and W Jaikla. Current controlled current conveyor transconductance amplifier (CCCCTA): A building block for analog signal processing. Electr. Eng. 2008; 90, 443-53.

[27] HP Chen, YS Hwang and YT Ku. Voltage-mode and current-mode resistorless third-order quadrature oscillator. Appl. Sci. 2017; 7, 179.

[28] T Bumrongchoke, W Jaikla and M Siripruchyanun. An electronic controllable simple current-mode oscillator using single MO-CCCCTA and grounded capacitors. In: Proceedings of the $1^{\text {st }}$ International Conference on Technical Education, Bangkok, Thailand. 2010, p. 217-20.

[29] P Silapan, C Tanaphatsiri and M Siripruchyanun. Current controlled CCTA based novel grounded capacitance multiplier with temperature compensation. In: Proceedings of the Asia Pacific Conference on Circuits and Systems, Macao, China. 2008, p. 1490-3.

[30] N Pandey, R Bazaz and R Manocha. MO-CCCCTA based floating positive and negative inductors and their applications. J. Electr. Comput. Eng. 2011; 2011, 150354.

[31] SV Singh, S Maheshwari and DS Chauhan. Electronically tunable current-mode SIMO/MISO universal biquad filter using MO-CCCCTAs. Int. J. Recent Trends Eng. Tech. 2011; 3, 36-41.

[32] HP Chen and WS Wang. Electronically tunable current controlled current conveyor transconductance amplifier-based mixed-mode biquadratic filter with resistorless and grounded capacitors. Appl. Sci. 2017; 7, 244. 